Journal of Case Reports 2018;8(1):64-66

\title{
Post Myocardial Infarction Ventricular Septal Rupture
}

\author{
Dheeraj Nair, Gebran Manzoor Monga, Kanjam Lakshmi, Chintala Chiranjeevi \\ Department of Emergency Medicine, Max Superspeciality Hospital, Vaishali, Ghaziabad, Uttar Pradesh, India.
}

Corresponding Author:

Dr. Gebran Manzoor Monga

Email: jibranmonga@gmail.com

This is an Open Access article distributed under the terms of the Creative Commons Attribution License (creativecommons.org/ licenses/by/3.0).

Received Accepted Published
January 24, 2018

March 1, 2018

March 10, 2018

\begin{abstract}
Background: Ventricular septal rupture (VSR) is a rare and lethal complication of acute myocardial infarction. Case Report: A 56 year old male following acute myocardial infarction (MI) was discovered to have ventricular septal (VS) rupture. Cardiac echocardiography (ECHO) confirmed the VS rupture. Conclusion: Usually MI is diagnosed by electrocardiography but in case of any physical finding we must do an cardiac ECHO. This case emphasizes the importance of echocardiography following an acute MI.
\end{abstract}

Keywords: Echocardiography, Electrocardiography, Myocardial Infarction, Ventricular Septum, Ventricular Septal Rupture.

\section{Introduction}

Ventricular septal rupture (VSR) is a rare complication of acute myocardial infarction with important hemodynamic consequences. Spontaneous closure is extremely rare. Without a rapid diagnosis and correction by surgical intervention, the short-term mortality of these patients is higher than $90 \%$ [1-3]. We report the case of a patient with acute myocardial infarction and a ventricular septal rupture. Early diagnosis was obtained in the emergency, based on clinical examination and echocardiography.

\section{Case Report}

A 56 year old male was referred to our hospital with complaints of chest pain and shortness of breath for one day which had progressively worsened since morning. Electrocardiography (ECG) done in outside hospital showed ST elevation in anterior leads suggestive of acute anterior wall myocardial infarction (AWMI). The patient was recently diagnosed as diabetic and was taking oral hypoglycemic agents. Family history was not suggestive for any cardiac disorder.

On arrival to emergency, patient was conscious, oriented and was profusely sweating.
Patient was afebrile and blood pressure was 90/60 $\mathrm{mmHg}$ with a heart rate of 110 beats/minute. Oxygen saturation was $92 \%$ on right arm. Physical examination revealed a systolic murmur. Initial resuscitation was started and patient was put on $4 \mathrm{~L} / \mathrm{min}$ of oxygen and intravenous fluid. Tablet ecospirin $325 \mathrm{mg}$, ticagrelor $180 \mathrm{mg}$, atorvastatin $80 \mathrm{mg}$ and injection heparin $5000 \mathrm{IU}$ were also given. A repeat ECG and urgent echocardiography (ECHO) were done in emergency in view of systolic murmur found on clinical examination. Fig.1,2 show ECG done outside before admission and ECG done in emergency after admission. Cardiac echocardiography showed one $\mathrm{cm}$ ventricular septal defect at apex, regional wall motion abnormalities, hypokinetic apico-lateral mid antero-lateral wall, and $30 \%$ left ventricular ejection fraction.

After confirming the diagnosis and within 15 minutes patient was shifted to cath lab where intra-aortic balloon pump (IABP) was inserted and angiography was done which revealed $100 \%$ left anterior descending (LAD) artery occlusion and plain balloon angioplasty to LAD was done. The patient was subsequently shifted to cardiothoracic and vascular surgery where he was electively 


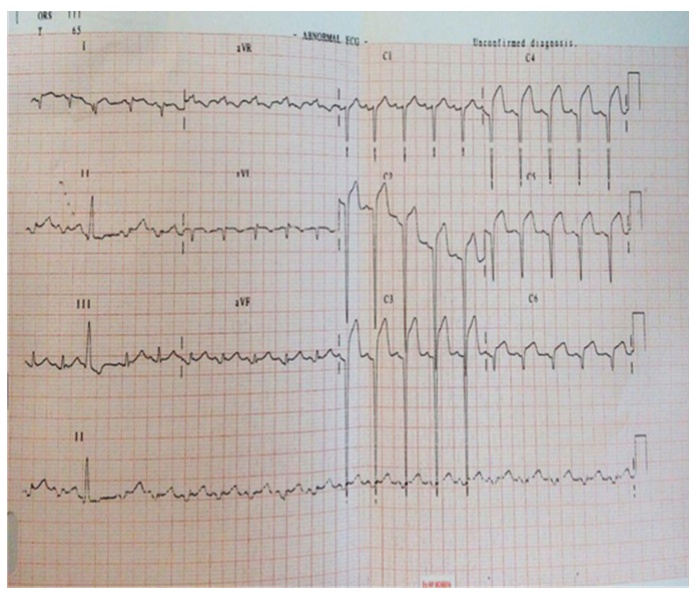

Fig.1: ECG before admission.

intubated and taken up for surgery for ventricular septal rupture.

After VSD repair patient was on IABP and ionotropic support. By $2^{\text {nd }}$ post-operative day patient got hemodynamically stable and was extubated. On $3^{\text {rd }}$ post-operative day, patient had sudden respiratory arrest and was immediately resuscitated and re-intubated and initiated on mechanical ventilation. On $4^{\text {th }}$ post-operative day he was weaned from IABP but ventilatory support continued. Chest X-ray revealed right pneumothorax for which inter-costal chest drain was inserted. On $5^{\text {th }}$ post-operative day, he was weaned off and extubated. After that the patient was hemodynamically stable till the day of discharge and finally the patient was discharged in stable condition.

\section{Discussion}

VSR is a rare but serious complication of acute myocardial infarction that is, in almost all cases, fatal without early surgical intervention. It had an incidence of $1-3 \%$ in the era before reperfusion therapy, decreasing with the introduction of thrombolytic therapy [1-3]. VSR is more infrequent than a rupture of the ventricular free wall. Women are affected more commonly than men $[2,4]$. Other risk factors are age and hypertension [5]. VSR usually occurs 2-8 days after the infarction and

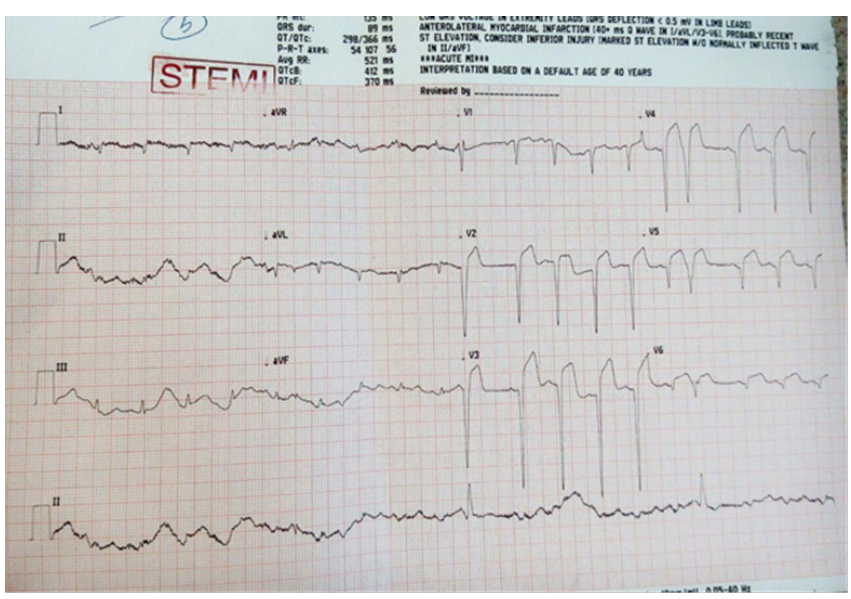

Fig. 2: ECG done in emergency department.

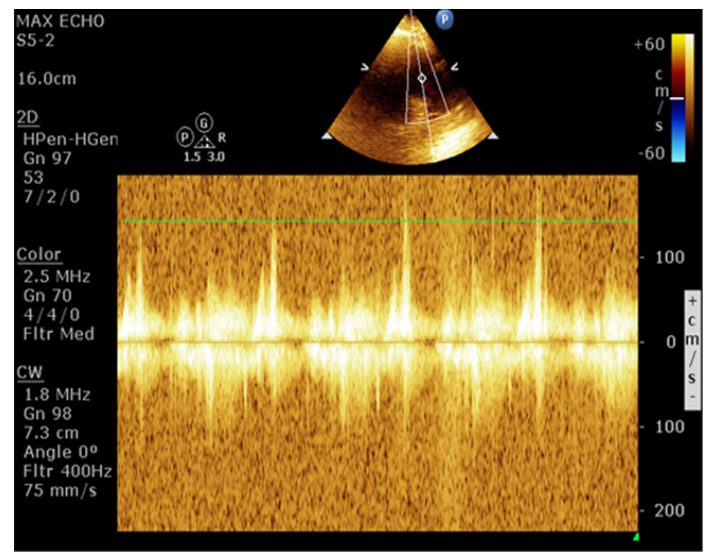

Fig.3: Echocardiography showing $1 \mathrm{~cm}$ VSD defect at apex.

often precipitates cardiogenic shock. There are a few reported cases of silent myocardial infarction followed by an asymptomatic VSR or presenting as chronic congestive heart failure [4]. The size of the defect determines the magnitude of the leftto-right shunt and consequently the hemodynamic deterioration, which affects survival. Complete spontaneous closure of such an acquired defect is extremely rare [6].

There are three types of VSR (the original classification made by Becker and van Mantgem was for free-wall rupture): type I is abrupt tear in the wall without thinning; type II results due to infarcted myocardium eroding before rupture and is covered by a thrombus; and type III represents the perforation of a previously formed aneurysm 
[4]. Infarction associated with a ventricular septal rupture (VSR) is usually transmural and extensive. About $60 \%$ of VSRs occur with infarction of the anterior wall, $40 \%$ with infarction of the posterior or inferior wall. Posterior VSR may be accompanied by mitral valve insufficiency secondary to papillary muscle infarction or dysfunction [3]. The prognosis for posterior VSD is worse because of associated right ventricular involvement and papillary muscle dysfunction [2].

There are two main surgical techniques for post-myocardial VSD repair: one uses patch closure of VSD with infarct excision and the other (this technique was used in this case) uses infarct exclusion [5]. The latter technique is now more commonly used as it has better results. Percutaneous device closure of residual VSD after surgical repair can also be done in cases where an important shunt persists. With timely surgical intervention the mortality rate can be brought down to $30-40 \%$ from $90 \%$.

\section{Conclusion}

The clinician needs to be aware of all the cardiovascular complications following acute MI. As clearly shown by this case, life threatening VS rupture can occur following acute MI. When considering the complications following acute MI the cardiologists should also consider the possibility of VS rupture.
Contributors: GM: manuscript writing, patient management; $\mathrm{DN}, \mathrm{KL}$ : manuscript editing, patient management; CC: critical inputs into the manuscript. GM will act as guarantor. All authors approved the final version of this manuscript.

Funding: None; Competing interests: None stated.

\section{References}

1. Birnbaum Y, Fishbein MC, Blanche C, Siegel RJ. Ventricular septal rupture after acute myocardial infarction. N Engl J Med. 2002;347:1426-1432.

2. Moreyra AE, Huang MS, Wilson AC, Deng Y, Cosgrove NM, Kostis JB. Trends in incidence and mortality rates of ventricular septal rupture during acute myocardial infarction. Am J Cardiol. 2010;106:1095-1100.

3. Crenshaw BS, Granger CB, Birnbaum Y, Pieper KS, Morris DC, Kleiman NS, et al. Risk factors, angiographic patterns, and outcomes in patients with ventricular septal defect complicating acute myocardial infarction. GUSTO-I (Global Utilization of Streptokinase and TPA for Occluded Coronary Arteries) trial investigators. Circulation. 2000;101:27-32.

4. Lopez-Sendon J, Gurfinkel EP, Lopez de Sa E, Agnelli G, Gore JM, Steg PG, et al. Factors related to heart rupture in acute coronary syndromes in the global registry of acute coronary events. Eur Heart J. 2010;31:1449-1456.

5. French JK, Hellkamp AS, Armstrong PW, Cohen E, Kleiman NS, O'Connor CM, et al. Mechanical complications after percutaneous coronary intervention in ST-elevation myocardial infarction (from APEXAMI). Am J Cardiol. 2010;105:59-63.

6. Keeley EC, Boura JA, Grines CL. Primary angioplasty versus intravenous thrombolytic therapy for acute myocardial infarction: a quantitative review of 23 randomised trials. Lancet. 2003;361:13-20. 